attempts either to explicate or fend off tacit value-driven concerns and opinions.

In Global Change and the Earth System, knowledge claims - that contemporary views are actually true - are often presented as definite explanations; examples include the huge extinction rate in Figure 1.7, and the reliance on the often-used but nevertheless questionable 'wiggle matching' technique. Another example is the claim that climate (in terms of an unexplained "Atmospheric Circulation Index") is the only factor that affects catches of Japanese or European sardines, with social factors, such as the Second World War, playing only a minor role. The authors often adopt the unsatisfactory practice of relating a host of changes to ongoing anthropogenic change, without systematic attempts at formal detection and attribution.

The examples that are adduced in this way seem to be biased towards deleterious effects. Thus, the book is a good demonstration that the environmental sciences are driven not only by curiosity and reductionist interests for detailed processes, but by an endeavour to integrate different sorts of often uncertain and contested knowledge claims from a broad field of disciplines - in an area that has high stakes. The result is an effort with a normative agenda of improving or saving the world.

I am sympathetic to this message, but as a scientist I think we must strive for objectivity (as far as possible) and avoid any overselling. Downplaying uncertainty is not useful, except perhaps for a limited time and a small audience. In the long term, this is not a sustainable approach. We can already see that large parts of the public and politicians, in both Europe and the United States, no longer trust many of the knowledge claims advanced by environmental scientists. Public concern about the state of the environment has begun to decline in recent years. Some may even erroneously see Bjørn Lomborg's The Skeptical Environmentalist (reviewed in Nature 414, 149; 2001) as the other side of the coin to this IGBP volume.

The authors of Global Change and the Earth System believe that "any complete analysis of the consequences of global change must go well beyond scientific and economic considerations to fundamental moral and ethical values". This is certainly true, but the book lacks an analysis of the complex history of the moral ideals in the cultural, ideological and political foundations of the modern environmental sciences. For this, readers can turn to such books as Ludwik Fleck's Genesis and Development of a Scientific Fact (University of Chicago Press, 1979) or Clarence Glacken's Traces on the Rhodian Shore (Cambridge University Press, 1967).

Hans von Storch is at the Institute for Coastal Research, GKSS Research Centre, Geesthacht 21502, Germany.

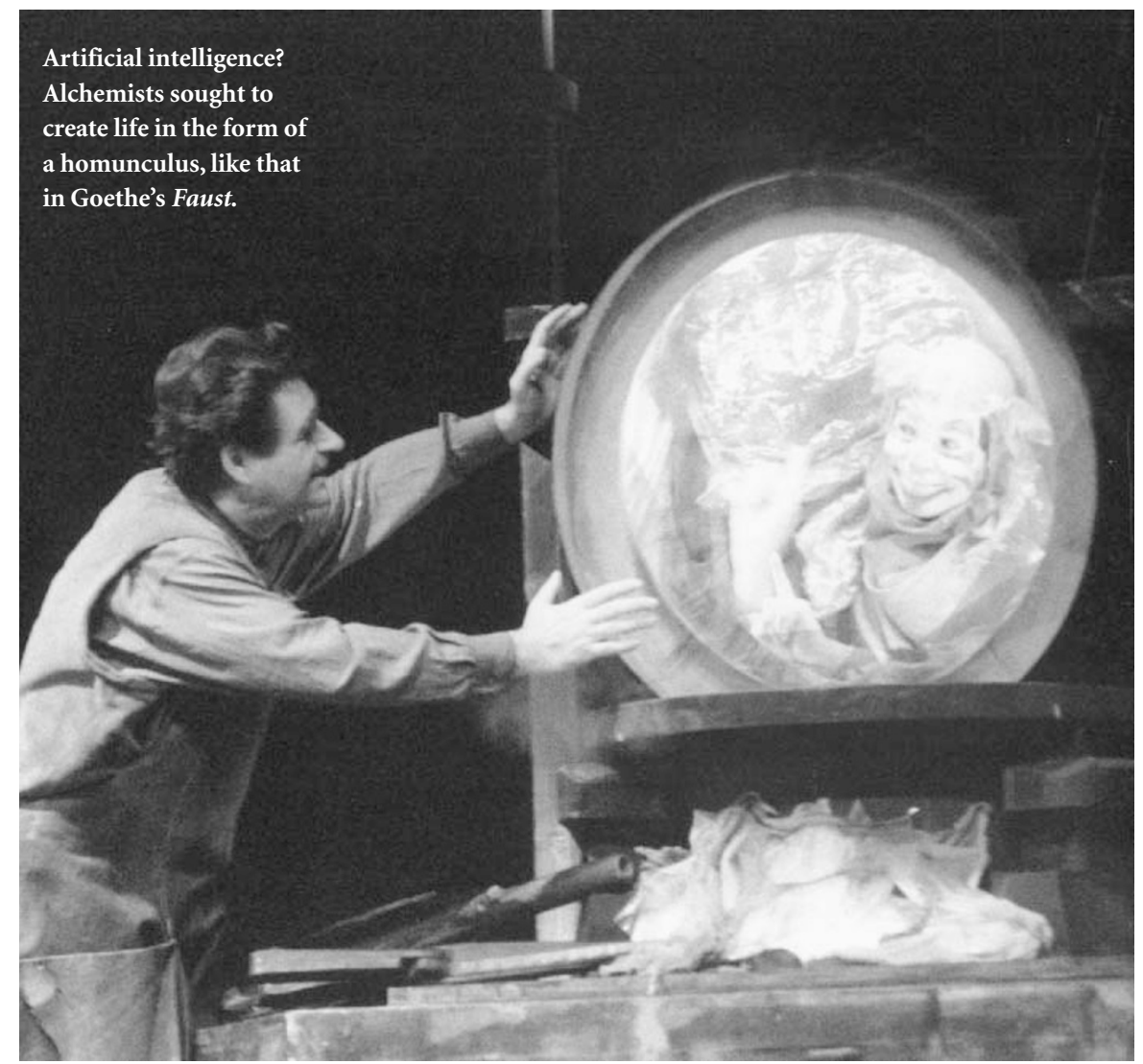

\section{Improving on nature}

\section{Promethean Ambitions: Alchemy and the Quest to Perfect Nature} by William R. Newman

University of Chicago Press: 2004. 352 pp.

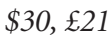

\section{David Knight}

There is nothing new under the sun, or so we are told. People worry about the artificial and the synthetic, as opposed to the natural; they pay extra for organic food, are concerned about genetic modification, and pontificate about bioethics, stem-cell research and cloning. All these things seem very modern, the fruit of progress in biochemistry, molecular biology and genetics; the oldest example would seem to be Justus Liebig's advocacy of inorganic fertilizers in the hungry 1840 s.

Not long before that, his friend Friedrich Wöhler had synthesized urea, in an attempt to provide evidence for atoms and their rearrangement, rather than to break down the organic/inorganic distinction. Processes and conditions in living organisms are very different from those in test-tubes, however, so although the end product might be the same, he did not replicate the reaction that creates urea in organisms. Human artfulness was still limited; perhaps nature was not after all a laboratory.

William Newman shows that debates about simulating, replicating and perfecting nature go back much further than this, however. Whereas we come to these debates through modern chemistry and biology, medieval and early modern authors approached them through alchemy. Modern chemists tend to look at alchemy askance, as delusion, confidence trickery or occultism, leading to disgrace, beggary and early death. But some, Michael Faraday among them, had a degree of sympathy with the idea that all the metals could not be irreducibly different indestructible entities, and Ernest Rutherford cheerfully referred to his work as modern alchemy. Newman is prominent among the historians of science who have shown how important alchemy was as part of the serious 'chymistry' of Robert Boyle, Isaac Newton and their contemporaries. In this book, he looks at the divide between 'art', which used to mean anything productive involving artifice and forethought, and 'nature', as illuminated in discussions of, and laboratory and clinical practice in, alchemy.

If something were to be made from base metal that had all the properties of gold, would it be gold? Or is there some essence that distinguishes the natural from the ersatz? Are 'species', whether of metals or of creatures, God-given and immutable?

Astronomy, contemplating the starry heavens, was well-suited to natural theology, for God could be praised for His wisdom and grandeur. But alchemy, and the practical spin-offs that led to pigments, drugs and distillates, including alcohol, seemed to be an attempt to improve the world; God 
Magnificent mayflies

Gaylord Schanilec is hooked on fishing flies that imitate nature.

\section{Colin Martin}

Inspiration can be found anywhere. Gaylord Schanilec, wood engraver, fine printer and trout fly-fisherman found it on a river bank, in the form of the common mayfly.

Schanilec owns Midnight Paper Sales, a private press that publishes small, limited editions of illustrated books, often related to local history or geography. He designs, engraves and prints the books, and often writes the text. Each book project begins with an idea that evolves gently into the shape of the final book, a process that can take years. He is now hard at work illustrating and writing an as-yet untitled book on the species of mayflies (Ephemeroptera) found in his local rivers.

The idea for the book came to him in the summer of 2001 when, as usual, he spent as much time as he could fishing. This gave him plenty of time to contemplate the artificial fishing flies, hand-tied to imitate mayflies, with which he baited his hook. Trout are a major natural predator of mayflies in the wild, and trout fishermen have for centuries used local knowledge to tie appropriate artificial flies, called dry flies, as bait. This year, for example, is the sesquicentennial of Greenwell's Glory, a dry fly first tied by William Greenwell in 1854.

Not wishing to rely solely on fishermen's folklore, in the winter of 2001 Schanilec consulted Clarke Garry, a biologist at the University of Wisconsin at River Falls, who studies insect life in local trout streams. Under Garry's guidance, Schanilec bought a microscope, specimen vials and preservative agents, and developed techniques for collecting, preserving and documenting mayflies. $\mathrm{He}$ also read widely around his subject, including two late-nineteenth-century books by Frederick M. Halford, Dry Fly Fishing in Theory and Practice and Dry Fly Entomology, the highly prized special edition of which includes samples of dry flies.

Entomologists have now identified about 2,000 species of mayfly, some 150 of which can be found near Schenilac's home in the river hamlet of Stockholm, on the southern prairie of Minnesota and Wisconsin. Throughout the 2002 fly-fishing season, Schanilec collected hundreds of specimens, using information provided by local fly-fishermen on where and when to find particular species, such as Hexagenia limbata on the lower Rush River and Ephemerella subvaria on particular stretches of the south branch of the Whitewater River. He has so far selected seven of these species for wood-cutting, including E. subvaria. Garry described them taxonomically and identified them for him.

Schanilec makes painstakingly detailed drawings. He then carves his final images into hard blocks of end-grain wood using sharp, metal gouging tools, to produce precisely detailed engravings from which he prints distinctive images in several colours. Reduction cutting - carving away more of the surface of the wood block between printings allows him to print two or more colours from the

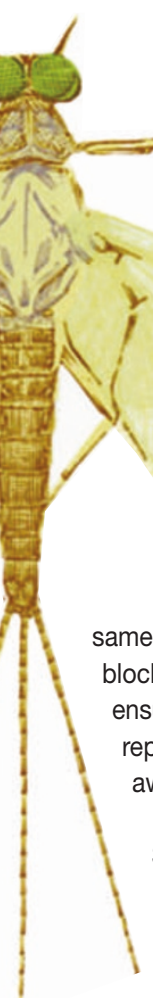

same block, rather than carve a separate block for each colour. This technique ensures exact registration but prevents reprinting, as the areas that have been cut away cannot be reused.

Using a letterpress printing press, Schanilec balances text and illustration on the pages he prints. The mayfly book, which will include engravings of 12 mayflies, including one of $E$. inermis (shown here), will be published in autumn next year in three editions: a large edition of portfolios of loose prints; a standard book, including both Garry's taxonomic descriptions and trout fishermen's folklore for each species bound alongside the prints; and a special edition, issued with hand-tied flies imitating each species, and an extra set of prints.

There is something rather magnificent about Schanilec's enterprise in capturing this most ephemeral order of insects between the covers of finely bound books. It recalls the remarkable eighteenth-century collaborations between artists and scientists in the Enlightenment.

Colin Martin is a writer based at 32 Woodstock

Road, London W4 1UF, UK. had left it to us to discover oil paints, milk of magnesia and whisky. We were (perhaps) better off as a result, but the natural theologian might be uneasy at the busy chymists' activities. And when naturally occurring substances were apparently made artificially, some were sceptical about whether they were exactly the same. Alchemists claimed that the processes by which gold was supposed to be generated in the bowels of the Earth were merely speeded up in their furnaces, but critics were not convinced, some seeing devilment lying behind any apparently successful transmutation.

Alchemists were not simply fixated on gold; they also sought not only to prolong life, but to synthesize it. Newman explores two routes to this end. The first was based on Jewish stories about the golem, made like Adam from the dust and brought to life (and destroyed when necessary) through Hebrew words. A golem lacked a rational soul, and so was not human. The other tradition was a kind of male parthenogenesis, in which women (the source of flesh and blood) could be bypassed and a homunculus grown in a glass vessel from semen. The homunculus often appeared in alchemical pictures, and most famously in Johann Wolfgang von Goethe's play Faust. The homunculus was a spirit, unable to survive outside his flask; but from within it he could expound wisdom that was unavailable to ordinary mortals weighed down by their bodies. In this connection, Newman provides an interesting section on Paracelsus, the genius or charlatan who brought chymistry into medicine, with his sexual hang-ups and fascination with phoenix-like 'rebirths' through fire.

The ethical problems facing Newman's cast of characters were hypothetical — after all, alchemy didn't work. But in an age of test- tube babies, Dolly the sheep and a vast array of synthetic chemicals, they are real enough.

Newman ends with a learned discussion of experiment - emphasizing that alchemy was an investigative science, carried on in the laboratory rather than the armchair - from medieval times up to Francis Bacon, Boyle, Newton and Margaret Cavendish. We meet artisans such as Bernard Palissy (who was 'making' fossils), as well as scholastic logicians. We are reminded that the 'scientific revolution' was not simply a matter of a new astronomy and a new physics. Rather, it was heavily dependent on the experimental tradition and critical thinking about analysis and synthesis. Alchemy would ultimately give birth not to a homunculus, but to the new chemistry.

David Knight is in the Department of Philosophy, University of Durham, 50 Old Elvet,

Durham DH1 3HN, UK. 